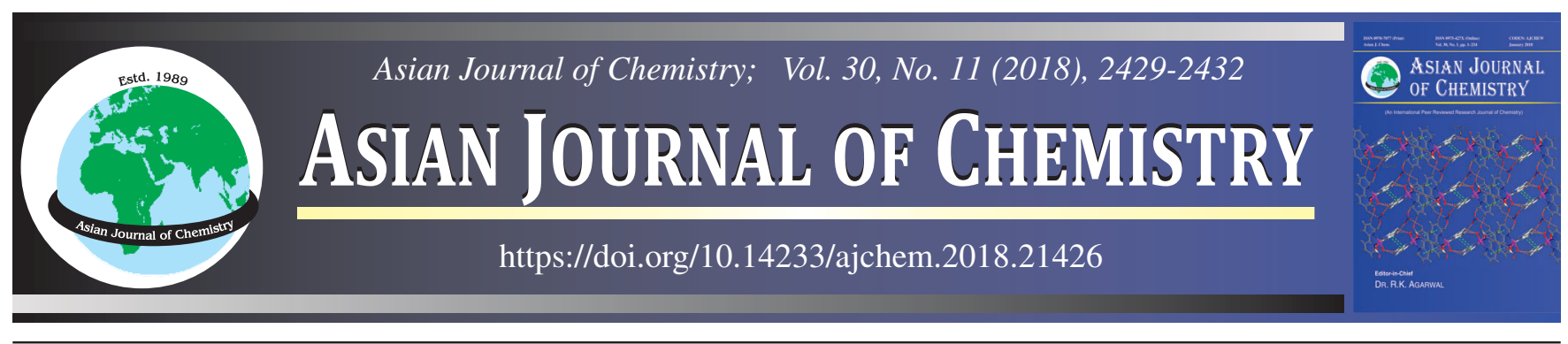

\title{
Preparation and Characterization of Carbon Nanotubes using Carbon Black by Electrochemical Technique with Anodic Aluminium Oxide
}

Jawad K. Oleiwi ${ }^{1}$, Rana Afif Majed Anaee ${ }^{1, *}$ and SafaA Hashim RadhI ${ }^{2}$

${ }^{1}$ Department of Materials Engineering, University of Technology, Baghdad, Iraq

${ }^{2}$ College of Engineering, University of Kufa, Kufa, Iraq

*Corresponding author: E-mail: dr.rana_afif@yahoo.com

Received: 5 May 2018;

Accepted: 6 July 2018;

Published online: 27 September 2018;

AJC-19089

| This study describes preparation and characterization of carbon nanotubes (CNTs) by anodic aluminium oxide (AAO) template assisted electrochemical deposition. A highly ordered array of cylindrical designed pores of anodic aluminium oxide was obtained from anodizing aluminum to use it as a template for deposition of carbon nanotubes. The fabrication of carbon nanotubes was done using moraine of micrometer sized carbon black with diameter range of 0.5-75 $\mu \mathrm{m}$. The characterization of carbon nanotubes was done by FTIR, SEM and AFM indicating the formation of carbon nanotubes within anodic aluminium oxide template by electrodeposition at room temperature. FTIR spectrum indicated the presence of peaks of $\mathrm{CH}_{\mathrm{x}}$ group associated with $\mathrm{O}-\mathrm{H}$, in addition to appear $\mathrm{COOH}$ group after functionalization of carbon nanotubes with $\left(\mathrm{HNO}_{3}-\mathrm{H}_{2} \mathrm{SO}_{4}\right)$ mixture to obtain functionalized carbon nanotubes (F-CNTs). The SEM morphology confirmed the fabrication of nanotube by appearing opened ends of tubes with nano dimensions. The atomic force microscopy analysis gave smother surface with more average diameters from 66.3 to $77.21 \mathrm{~nm}$ for F-CNTs compared with carbon nanotubes due to formation carboxylic groups.

Keywords: Carbon nanotubes, Carbon black, Anodized aluminum oxide, Electrochemical deposition.

ᄂ _ - - - - - - - - - - - - - - - - - - - - - - - - - - - - -

\section{INTRODUCTION}

Carbon nanotubes were discovered in 1990s, they are like graphite sheets rolled up with fullerene end caps and there are two types of carbon nanotubes; single wall with a diameter of $\approx 1.4 \mathrm{~nm}$ and multiwall nanotubes with an outer diameter of $30-50 \mathrm{~nm}$ [1]. These nanotubes are strongest and hardest material due to the chemical bonding in their structure which based on $s p^{2}$ orbital bond [2] in addition to the flexible hexagonal network of carbon atoms $[3,4]$, while their morphology is different and depended on the methods of preparation $[5,6]$. There are many used methods to prepare carbon nanotubes, among them is using anodic aluminum oxide (AAO) template to deposit carbon nanotubes in addition to nanodots, nanowires, nanopillars, etc. $[7,8]$. Other methods of preparation carried out by arc discharge $[9,10]$, chemical vapor deposition (CVD) [11,12] and laser ablation $[13,14]$.

This work aims to convert the micrometer sized material to nanostructured material by a simple method. Carbon nano- tubes were fabricated by templates of anodized aluminum oxide (AAO) through simple electrochemical deposition using locally available materials (carbon black) at room temperature and then functionalized them for different applications. The present method represents simple way to synthesis with excellent uniformity of carbon nanotubes obtained and the short process time compared with the conventional carbon nanotube synthesis methods, where the synthesis of carbon nanotubes by Dadras and Faraji [15] needs high energy using microwave oven and the synthesis using Ni/AAO needs catalyst to prepare carbon nanotubes from waste plastics by Liu et al. [16] and the method of Hou et al. [17] by anodized aluminum oxide (AAO) is complex method includes several steps such as carbonize organic polymer within anodized aluminum oxide (AAO) and then deposit pyroltic carbon from gaseous hydrocarbons [17].

\section{EXPERIMENTAL}

Synthesis of anodized aluminum oxide (AAO): Aluminum foil with purity $99.99 \%$ and area of $(10 \mathrm{~cm} \times 10 \mathrm{~cm})$ and

This is an open access journal, and articles are distributed under the terms of the Creative Commons Attribution-NonCommercial 4.0 International (CC BY-NC 4.0) License, which allows others to copy and redistribute the material in any medium or format, remix, transform, and build upon the material, as long as appropriate credit is given and the new creations are licensed under the identical terms. 
thickness $(0.3 \mathrm{~mm})$ was used as an anode in the electrochemical cell, while stainless steel $306 \mathrm{~L}$ used as a cathode in $0.3 \mathrm{M}$ oxalic acid. Ethanol, acetone, $3 \mathrm{M} \mathrm{NaOH}$, a mixture of $\left(\mathrm{H}_{3} \mathrm{PO}_{4}\right.$ $+\mathrm{H}_{2} \mathrm{CrO}_{4}$ ) acids and $5 \% \mathrm{H}_{3} \mathrm{PO}_{4}$ were used as a cleaning and treating reagents in addition to electrolytes for dissolving the template after deposition of carbon nanotubes. The anodization of aluminum was done with two steps according to the literature $[18,19]$.

Deposition of carbon nanotubes: Carbon electrode with a length of $12 \mathrm{~cm}$ and diameter of $1 \mathrm{~cm}$ was used as an anode in the electrochemical cell using prepared anodized aluminum oxide as a cathode with carbon nanopowder in $30 \mathrm{~g} / \mathrm{L}$ of boric acid. After deposition at 1.5 volt for $30 \mathrm{~min}$, deposited carbon nanotubes were filtered and washed with deionized water at room temperature. Carbon black (50 g) obtained from Babylon Tires factory was milled by planetary mill with balls for a period time $30 \mathrm{~h}$.

Functionalization of carbon nanotubes: Carbon nanotubes $(0.5 \mathrm{~g})$ as nanopowder was added to $250 \mathrm{~mL}$ of conc. $\mathrm{H}_{2} \mathrm{SO}_{4} /$ $\mathrm{HNO}_{3}$ with a ratio of $3: 1$. The mixture solution was then cooled and ultrasonicated for $30 \mathrm{~min}$ at $25-30^{\circ} \mathrm{C}$ using ultrasonic mixing liquid (MTI corporation: USA) and then centrifuged at 2500 rpm for $20 \mathrm{~min}$. Then, MWCNTs were washed with deionized water and centrifuged for several times. The additional step was purification the mixture by qualitative filter paper with $(0.1 \mu)$. Finally, carbon nanotubes were collected and dried in air for one week.

\section{RESULTS AND DISCUSSION}

Analysis of particle size of the started material (carbon black) is shown in Fig. 1, which indicates that the particle size is within micrometer. Fig. 2 shows the XRD pattern of carbon black which is a good agreement with JCPDS card No. 03-0401 for carbon as graphite with strongest peaks at $2 \theta=25.9225^{\circ}$ (002), $43.6464^{\circ}(101)$ and $77.5845^{\circ}(110)$. The FTIR of fabricated carbon nanotubes with two dominant peaks: 1649 and $3468 \mathrm{~cm}^{-1}$ (O-H). Several peaks (Fig. 3) in the range of 3000 $\mathrm{cm}^{-1}$ are attributed to $\mathrm{CH}_{\mathrm{x}}$ groups. The vibration at near 1593 $\mathrm{cm}^{-1}$ indicated the presence of cylinder like carbon structure (rolled graphene sheet). Several bands near $1580 \mathrm{~cm}^{-1}$ is referred to active modes in infrared spectrum and depending on the geometry of the carbon nanotube and its diameter as observed by Jishi et al. [20].

In the FTIR spectrum of functionalized carbon nanotubes, there are two dominant peaks viz., $3483 \& 1652 \mathrm{~cm}^{-1}$ and another

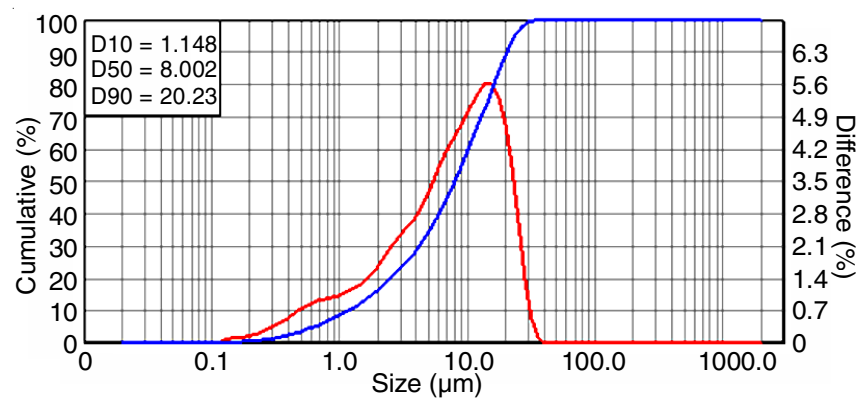

Fig. 1. Particle size analysis of carbon black

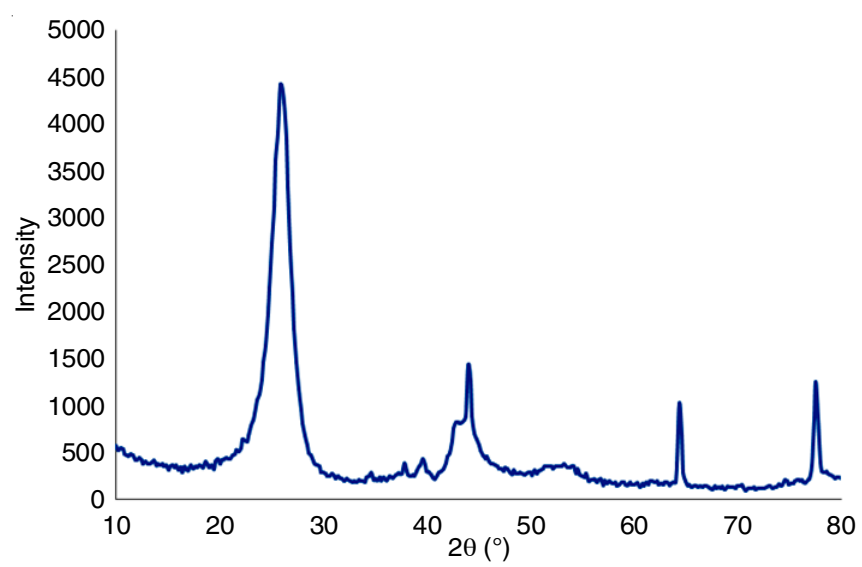

Fig. 2. XRD of carbon black

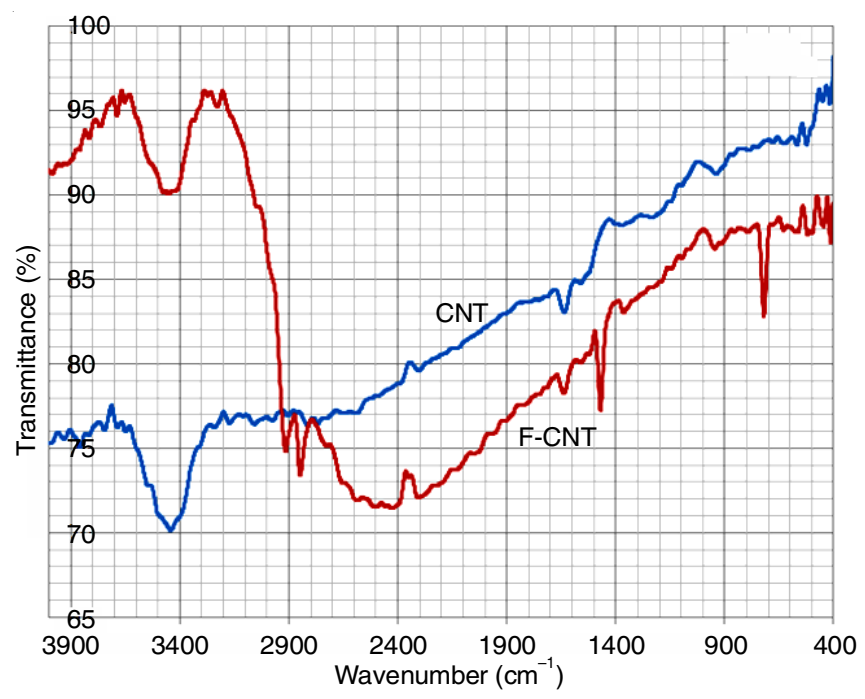

Fig. 3. FTIR spectra of CNTs and F-CNTs
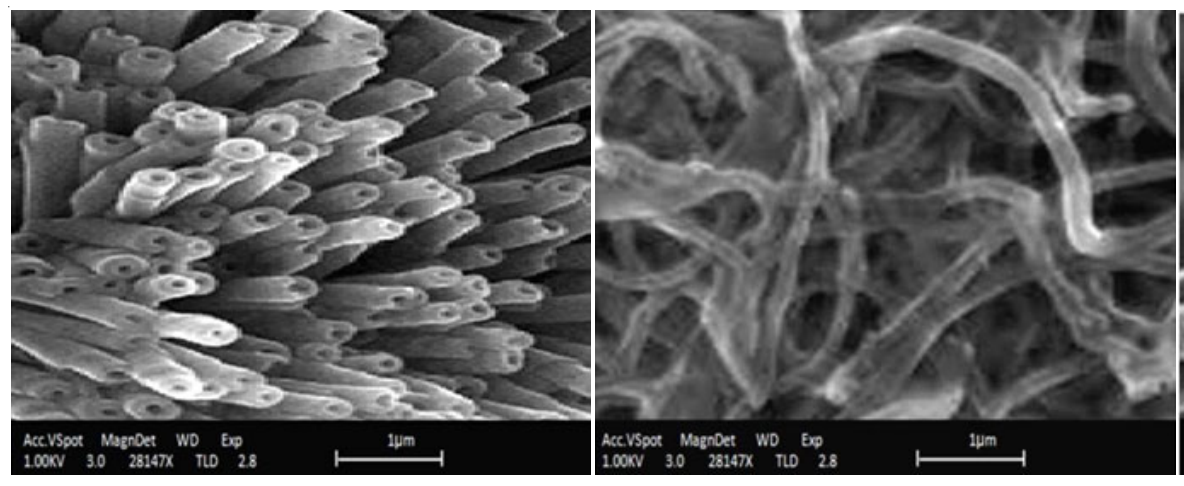

Fig. 4. SEM of carbon nanotubes

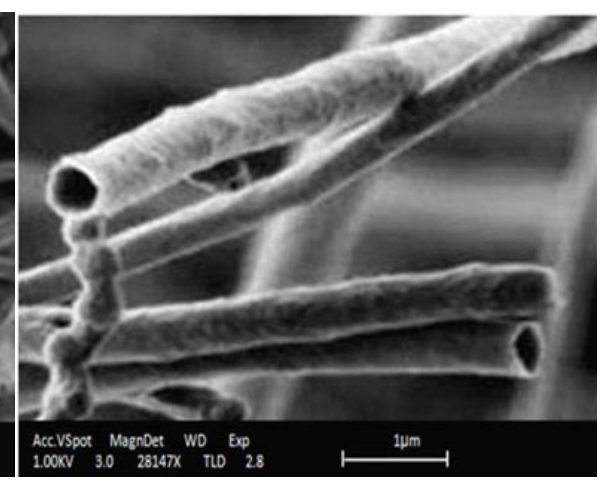

$1.00 \mathrm{KV} 3.0 \quad 28147 \mathrm{~K}$ TLD 2. 
peak at $1472 \mathrm{~cm}^{-1}$ agreed with the observation of Misra et al. [21]. The peak presented at $1450 \mathrm{~cm}^{-1}$ is a unique to MWCNTs as referred by Kouklin et al. [22]. The broader band at 3400 $\mathrm{cm}^{-1}$ is attributed to $\mathrm{COOH}$ groups, while several peaks in the range of $3000 \mathrm{~cm}^{-1}$ range are attributed to $\mathrm{CH}_{\mathrm{x}}$ groups [22].

SEM images of functionalized carbon nanotubes are shown in Fig. 4. These morphologies indicated the nanotubes after partially dissolved of AAO template which appeared as multi arrays (MWCNTs) having an outer diameter of 30-80 nm and inner diameter ranged between 8-15 nm. After complete dissolution of AAO, the nanotubes as associated here with a length of 10-20 $\mu \mathrm{m}$. While the morphology of single nanotubes confirm the obtaining tubes with opened end not nanowires or nanorods. The EDS analysis of carbon nanotubes is shown in Fig. 5 confirmed the generation of the carbon nanotubes under experimental conditions.

AFM images for CNTs and F-CNTs are shown in Figs. 6 and 7, respectively. These figures show $2 \mathrm{D}$ and $3 \mathrm{D}$ images for fabricated tubes, AFM gives information only about the length of nanotubes and approximate value of the bundles diameter. The functionalization gives more order in a carbon nanotube with less valley depth. Also, the functionalization of carbon

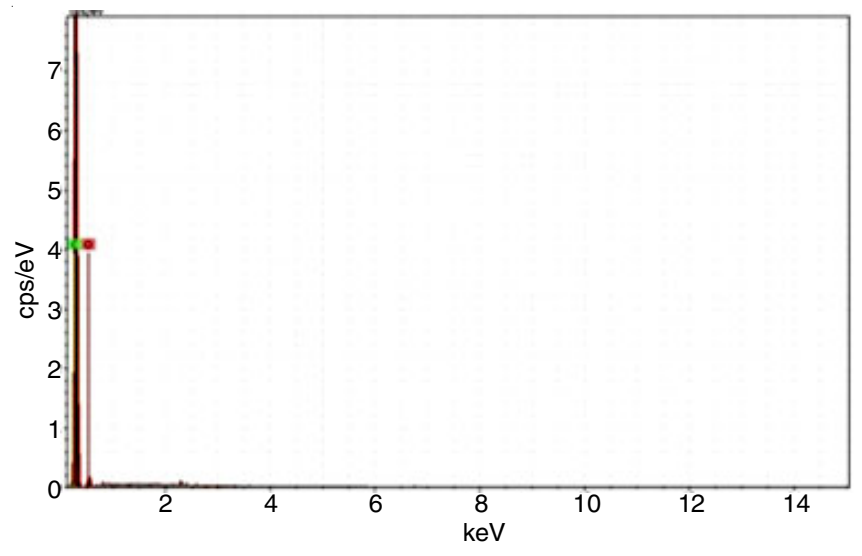

Fig. 5. EDS of carbon nanotubes

nanotubes gave a reduction in roughness average from 2.26 to $0.162 \mathrm{~nm}$ due to carboxylic groups which appeared due to functionalization and by formation $\mathrm{H}$-bonding, henceforth smoother surface obtained. Formed carboxylic groups gave more average diameters (Fig. 8), where average diameter was increased from 66.3 to $77.21 \mathrm{~nm}$. The diameters having less than $10 \%$ were decreased, while the diameters that more than $10-90 \%$ were increased.
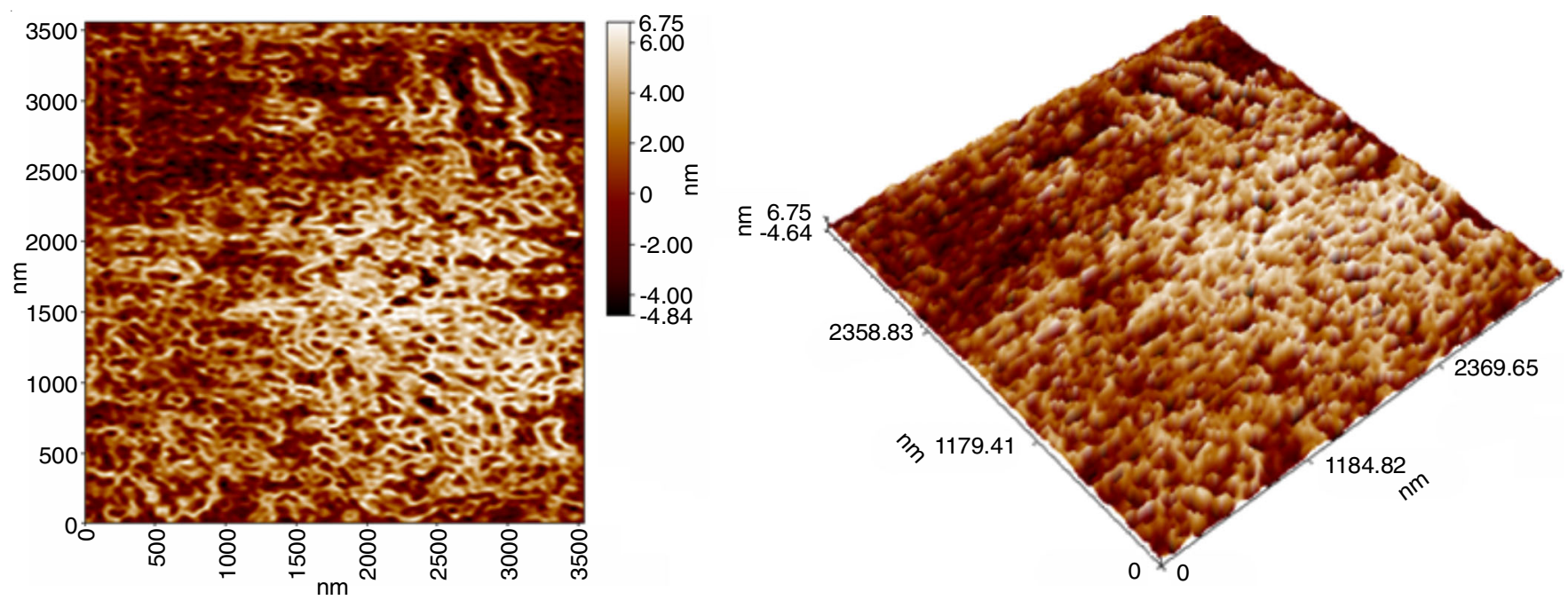

Fig. 6. AFM images of carbon nanotubes
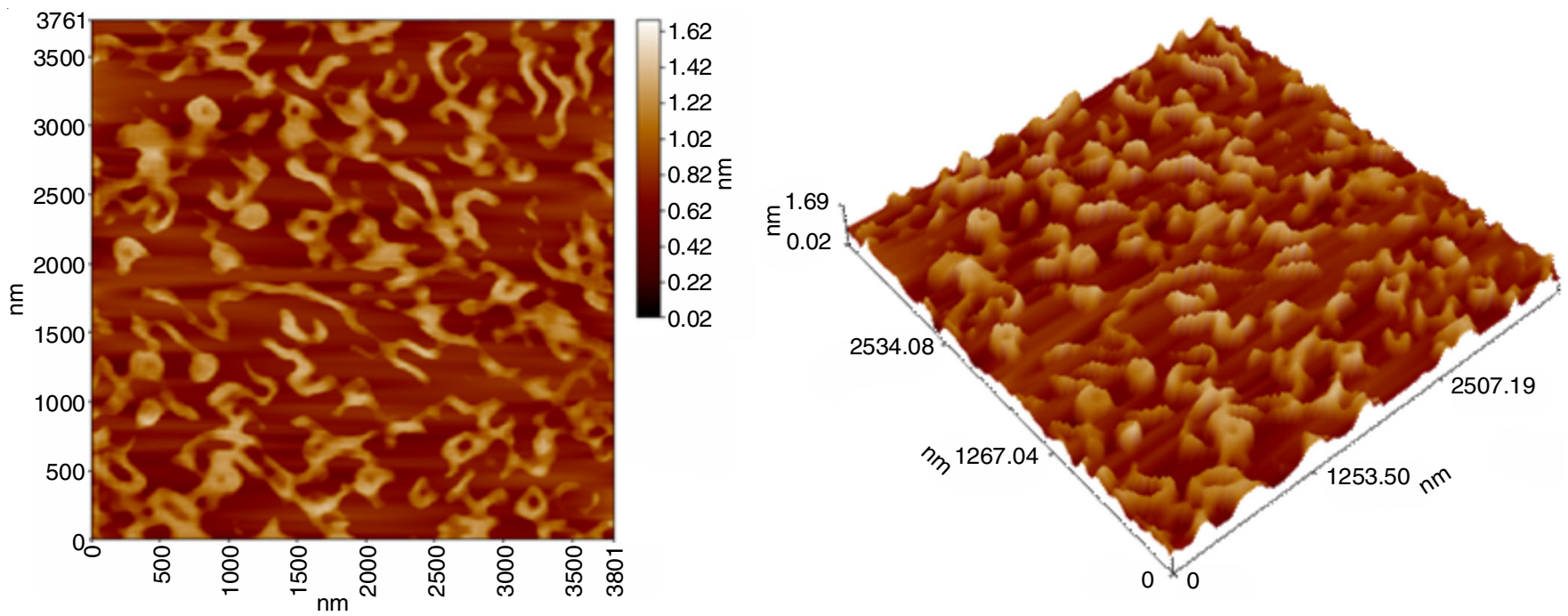

Fig. 7. AFM images of functionalized carbon nanotubes 

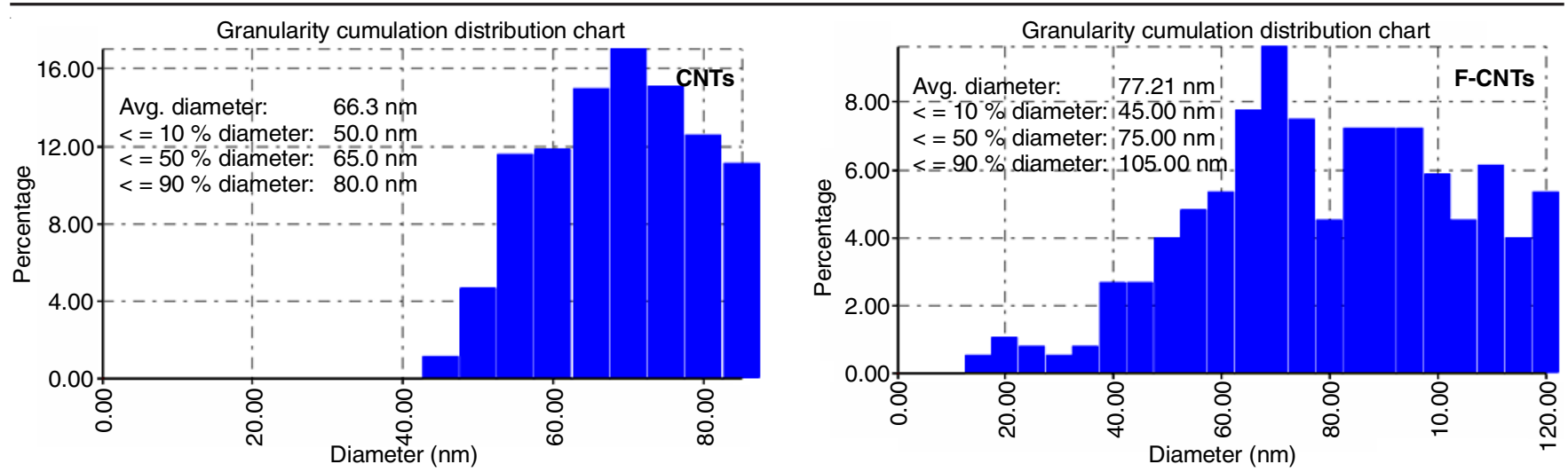

Fig. 8. Granularity accumulation distribution for CNTs and F-CNTs

\section{Conclusion}

In this research, carbon black was converted to carbon nanotube by a simple method at room temperature. The fabricated carbon nanotubes were characterized by SEM, EDS, FTIR and AFM. These characterization results confirmed the formation of carbon nanotubes. Then, functionalization of these carbon nanotubes was done to be used in many fields as reinforcement.

\section{CONFLICT OF INTEREST}

The authors declare that there is no conflict of interests regarding the publication of this article.

\section{REFERENCES}

1. F. Luisa and S. Duncan, Nanotechnologies: Principles, Applications, Implications and Hands-On Activities, European Commission (2013).

2. B. Peng, M. Locascio, P. Zapol, S. Li, S.L. Mielke, G.C. Schatz and H.D. Espinosa, Nat. Nanotechnol., 3, 626 (2008);

https://doi.org/10.1038/nnano.2008.211

3. D. Qian, G.J. Wagner, W.K. Liu, M.-F. Yu and R.S. Ruoff, Appl. Mech. Rev., 55, 495 (2002);

https://doi.org/10.1115/1.1490129.

4. K. Bordo, Ph.D. Thesis, Nanoporous Thin Film Templates for the Fabrication of Nanowires and Nanotubes, NanoSYD, Mads Clausen Institute University of Southern Denmark (2011).

5. S. Iijima, C. Brabec, A. Maiti and J. Bernholc, J. Chem. Phys., 104, 2089 (1996);

https://doi.org/10.1063/1.470966.

6. P.M. Chaudhari, S.C. Daswadkar and P.V. Kasture, J. Pharm. Res., 2 , 1179 (2009).

7. H. He, L.A. Pham-Huy, P. Dramou, D. Xiao, P. Zuo and C. Pham-Huy, BioMed. Res. Int., Article ID 578290 (2013); https://doi.org/10.1155/2013/578290.

8. G.D. Sulka, ed.: A. Eftekhari, Highly Ordered Anodic Porous Alumina, Formation, by Self-Organized Anodzing, section 1.2.1 Types of Anodic Oxide Film, In: Nanostructured Materials in Electrochemistry, WileyVCH Verlag GmbH \& Co. KGaA, Chap. 1 (2008).
9. D.S. Bethune, C.H. Kiang, M.S. de Vries, G. Gorman, R. Savoy, J. Vazquez and R. Beyers, Nature, 363, 605 (1993);

https://doi.org/10.1038/363605a0.

10. S. Iijima, Nature, 354, 56 (1991); https://doi.org/10.1038/354056a0.

11. R. Fu, M.S. Dresselhaus, G. Dresselhaus, B. Zheng, J. Liu, J. Satcher Jr. and T.F. Baumann, J. Non-Crystalline Solids, 318, 223 (2003); https://doi.org/10.1016/S0022-3093(02)01903-8.

12. G. Che, B.B. Lakshmi, C.R. Martin, E.R. Fisher and R.S. Ruoff, Chem. Mater., 10, 260 (1998); https://doi.org/10.1021/cm970412f

13. A. Thess, R. Lee, P. Nikolaev, H. Dai, P. Petit, J. Robert, C. Xu, Y.H. Lee, S.G. Kim, A.G. Rinzler, D.T. Colbert, G.E. Scuseria, D. Tomanek, J.E. Fischer and R.E. Smalley, Science, 273, 483 (1996); https://doi.org/10.1126/science.273.5274.483.

14. T. Guo, P. Nikolaev, A.G. Rinzler, D. Tomanek, D.T. Colbert and R.E. Smalley, J. Phys. Chem., 99, 10694 (1995); https://doi.org/10.1021/j100027a002.

15. S. Dadras and M. Faraji, J. Phys. Chem. Solids, 116, 203 (2018); https://doi.org/10.1016/j.jpcs.2018.01.039.

16. X. Liu, B. Shen, P. Yuan, D. Patel and C. Wu, Energy Procedia, 142, 525 (2017); https://doi.org/10.1016/j.egypro.2017.12.082.

17. P.X. Hou, C. Liu, C. Shi and H.M. Cheng, Chin. Sci. Bull., 57, 187 (2012); https://doi.org/10.1007/s11434-011-4892-2.

18. R.A. Anaee, A.H. Ali and A.R. Hassan, Asian J. Chem., 28, 2529 (2016); https://doi.org/10.14233/ajchem.2016.20078.

19. R.A. Anaee, A.H. Ali and A.R. Hasan, Int. J. Adv. Sci. Eng. Technol., 5, 29 (2017).

20. R.A. Jishi, L. Venkataraman, M.S. Dresselhaus and G. Dresselhaus, Chem. Phys. Lett., 209, 77 (1993); https://doi.org/10.1016/0009-2614(93)87205-H.

21. A. Misra, P.K. Tyagi, P. Rai and D.S. Misra, J. Nanosci. Nanotechnol., 7, 1820 (2007); https://doi.org/10.1166/jnn.2007.723.

22. N. Kouklin, M. Tzolov, D. Straus, A. Yin and J.M. Xu, Appl. Phys. Lett., 85, 4463 (2004); https://doi.org/10.1063/1.1812837. 